\title{
DO HEIGHT AND WEIGHT PLAY AN IMPORTANT ROLE IN BLOCK AND ATTACK EFFICIENCY IN HIGH-LEVEL MEN'S VOLLEYBALL?
}

\author{
Raini Stamm ${ }^{1}$, Meelis Stamm ${ }^{2}$, Aleksander Jairus ${ }^{1}$, \\ Reino Toop, Reeda Tuula ${ }^{1}$, Paulo Vicente João ${ }^{3}$ \\ ${ }^{1}$ School of Natural Sciences and Health, Tallinn University, Estonia \\ ${ }^{2}$ Estonian Defence Forces Headquarter \\ ${ }^{3}$ Sport Sciences, Exercise \& Health Department, University of Trás-os-Montes e \\ Alto Douro, Portugal.
}

\begin{abstract}
The research objective was to study the relationships of players' efficiency in attack and block with their anthropometric characteristics. Data on men's weight and height and their proficiency in the game were used. The subjects were the members of the Estonian, Italian, French and Croatian national volleyball teams who participated in Pool B of the European Championship. Data are given on men's height, weight, age, total number of spikes, attack errors, attacks won, efficiency of attack, total number of blocks, block errors, blocks won, and efficiency of block. In addition, the number of points won by men and their positions in the game are given. Minimums, maximums, standard deviations and means were calculated. To find correlations, Pearson's correlation analysis $(\mathrm{p}<0.05)$ was used. In our study, taller and heavier players proved to be more efficient at attack. Comparison of positions showed that middle blockers were taller and performed more blocks, setters were shorter and performed the least of attacks, and outside attackers and opposite attackers were of medium height and carried the greatest load of attack. As a conclusion, it was found that, in professional volleyball, height correlated with the efficiency of attack $(r=0.534 ; \mathrm{p}<0.05)$, and weight also correlated with the efficiency of attack $(\mathrm{r}=0.518 ; \mathrm{p}<0.05)$. There was no correlation between the anthropometric characteristics and block in volleyball at the professional level in our study. In volleyball, the greatest load at attack is carried by outside attackers
\end{abstract}


and opposite attackers, while middle blockers have the greatest load at block. Setters perform the smallest number of attacks.

Keywords: men; volleyball; efficiency; anthropometry; spiking; blocking

\section{INTRODUCTION}

Proficiency in volleyball depends on technical, tactical, physical, psychological and anthropometric factors $[1,3,6]$. Height gives players an advantage in activities near the net [2]. Opposite attackers are players in the team who have a great load of attack; thus they must have long legs and long arms [4]. Outside attackers are shorter and lighter, as they also have an essential role in reception, for which quicker mobility is needed [5]. For setters and liberos, speed and the ability to read the game are essential; for them height is not so significant. Towards the ends of sets, setters are sometimes replaced with taller players to strengthen the block, and this can lead to victory [9]. Considering the abovementioned, the objective of the current study was to study the relationships between the players' attack and block efficiency and their weight and height in Pool B of Men's European Volleyball Championship in 2015 where the participants were the national teams of Estonia, Italy, France and Croatia.

\section{MATERIAL AND METHODS}

The subjects included the members of the Estonian, Italian, French and Croatian national volleyball teams who participated in Pool B of the European Championship. Out of them, players were selected who performed at least 5 attacks or blocking elements above the net. This selection included 36 players. The proficiency data of all the 6 matches were recorded by Alar Rikberg, statistician of the Estonian national volleyball team, with the program Data Volley (2007). Men's height and weight were available on the homepage of the European Volleyball Confederation (CEV). As for proficiency in the game, the elements of attack and defence above the net were taken into account (block and attack); in addition, the total number of points won by performing these elements was calculated. In statistics of attack, all spikes, attack errors, attacks won and the efficiency of attack were studied. In statistics of defence, all blocks, block errors, blocks won and the efficiency of block were taken into consideration. The efficiency of the element was calculated for blocking by the following formula: 
The profficiency of the element was calculated for blocking by the following formula:

\section{The blocks won - block errors / total number of blocks $x 100$}

Data analysis was performed by MS Excel; to find correlations, Pearson's correlation analysis $(\mathrm{p}<0.05)$ was used. Correlations were found between anthropometric characteristics and all the statistical elements used in the study.

\section{RESULTS}

The mean height of the sample of men $(n=30)$ participating in Pool $B$ of the European Championship 2015 was $200.2 \mathrm{~cm}$ (SD 6.9). The height of the shortest player was $183 \mathrm{~cm}$ and that of the tallest player $211 \mathrm{~cm}$. The players' mean age was 27 years (SD 4.4). The oldest subject was 36 and the youngest 19 years old. The mean weight of the subjects was $93.5 \mathrm{~kg}$ (SD 9.2). The smallest weight was $72 \mathrm{~kg}$ and the greatest weight $114 \mathrm{~kg}$. (Table 1).

Table 1. Means and standard deviations of height, weight and age of men volleyballers according to their positions $(n=30)$

\begin{tabular}{lccc}
\hline & Weight kg $(\mathrm{n}=30)$ & Height $\mathrm{cm}(\mathrm{n}=30)$ & Age $(\mathrm{n}=30)$ \\
\hline Setter $(\mathrm{n}=5)$ & & & \\
\hline $\bar{x}$ & 81.600 & 191.400 & 28.600 \\
\hline SD & 8.173 & 5.770 & 7.334 \\
\hline Middle blocker $(\mathrm{n}=9)$ & & & 26.444 \\
\hline $\bar{x}$ & 99.667 & 206.889 & 3.711 \\
\hline SD & 6.144 & 3.018 & \\
\hline Outside hitter $(\mathrm{n}=9)$ & & & 26.111 \\
\hline $\bar{x}$ & 90.111 & 197.000 & 4.075 \\
\hline SD & 5.325 & 3.354 & 27.429 \\
\hline Opposite hitter $(\mathrm{n}=7)$ & & & 4.035 \\
\hline $\bar{x}$ & 98.286 & 202.143 & \\
\hline SD & 8.179 & 5.928 & 26.933 \\
\hline Overall $(\mathrm{n}=30)$ & & & 4.396 \\
\hline $\bar{x}$ & 93.467 & 200.233 & 36 \\
\hline SD & 9.15 & 6.869 & 19 \\
\hline Max & 114 & 211 & \\
\hline Min & 72 & 183 & \\
\hline & & & \\
\hline
\end{tabular}


Spikes were performed by 29 players in total (Table 2). The greatest number of attacks performed by one player in three matches was 92; this player was an opposite attacker. On average, 36 attacks per player (SD 29.6) were performed during the pool tournament. In the total of three matches, the tallest player performed 25 attacks, from which he scored 9 points and erred 6 times. This means that his efficiency of attack was $36 \%$. The player with the best efficiency of attack $(72.7 \%)$ performed 11 spikes, 8 of which were successful, and he never erred. Pearson's correlation analysis revealed that weight was in statistically significant correlation with the efficiency of attack $(r=0.518 ; \mathrm{p}<0.05)$. Height was also found to be in statistically significant correlation with the efficiency of attack $(r=0.534 ;(p<0.05)$. The number of attacks did not show any statistically significant correlation with height and weight. Neither did the anthropometric characteristics have any statistically significant correlation with the number of attack errors.

Table 2. Means and standard deviations of attacking performance of men volleyballers $(n=29)$

\begin{tabular}{lccccc}
\hline & $\begin{array}{c}\text { Total attacks } \\
(\mathbf{n}=\mathbf{2 9})\end{array}$ & $\begin{array}{c}\text { Successful } \\
\text { attacks } \\
(\mathbf{n}=\mathbf{2 9})\end{array}$ & $\begin{array}{c}\text { Attacks errors } \\
(\mathbf{n}=\mathbf{2 9})\end{array}$ & $\begin{array}{c}\text { Proficiency } \\
\text { of attack } \\
(\mathbf{n}=\mathbf{2 9})\end{array}$ & $\begin{array}{c}\text { Efficiency } \\
\text { of attack } \\
(\mathbf{n}=\mathbf{2 9})\end{array}$ \\
\hline $\bar{x}$ & 36.690 & 16.483 & 6.345 & 0.239 & 0.422 \\
\hline SD & 29.646 & 14.144 & 5.891 & 0.239 & 0.157 \\
\hline Max & 92 & 44 & 23 & 0.727 & 0.727 \\
\hline Min & 5 & 0 & 0 & -0.333 & 0 \\
\hline
\end{tabular}

Blocks were performed by 28 players in total (Table 3 ). The player who performed the greatest number of blocks (37) was a middle blocker. Out of the 37 blocks performed by the player, only 6 were successful, and he erred 20 times. The shortest player, whose height was $183 \mathrm{~cm}$, performed 22 blocks, 2 of which were successful, and he erred 8 times. Pearson's correlation analysis showed that height and weight had no statistically significant correlation with the number of blocks, block errors and efficiency of block.

The greatest number of points in all the matches was scored by an outside attacker who achieved 50 points in total. The tallest player scored 9 points and the shortest player 3 points. On average, 19 points were scored per player during the pool tournament (SD 15). Among the five greatest scorers, there were three opposite attackers and two outside attackers. 
Table 3. Means and standard deviations of blocking performance of men volleyballers $(\mathrm{n}=28)$

\begin{tabular}{lccccc}
\hline & $\begin{array}{c}\text { Total } \\
\text { blocks } \\
(\mathbf{n}=\mathbf{2 8})\end{array}$ & $\begin{array}{c}\text { Successful } \\
\text { blocks } \\
(\mathbf{n}=\mathbf{2 8})\end{array}$ & $\begin{array}{c}\text { Block } \\
\text { errors } \\
(\mathbf{n}=\mathbf{2 8})\end{array}$ & $\begin{array}{c}\text { Proficiency } \\
\text { of block } \\
(\mathbf{n}=\mathbf{2 8})\end{array}$ & $\begin{array}{c}\text { Efficiency } \\
\text { of block } \\
(\mathbf{n}=\mathbf{2 8})\end{array}$ \\
\hline $\bar{x}$ & 17.179 & 3.750 & 7.393 & -0.187 & 0.231 \\
\hline SD & 7.507 & 2.707 & 4.546 & 0.258 & 0.155 \\
\hline Max & 37 & 13 & 20 & 0.750 & 0.750 \\
\hline Min & 4 & 0 & 0 & -0.667 & 0.000 \\
\hline
\end{tabular}

The research revealed that the greater the total number of attacks, the greater was also the number of attacks won $(r=0.980 ; p<0.05)$ (Table 4$)$. Simultaneously, the greater total number of attacks was also accompanied by the greater number of attack errors $(\mathrm{r}=0.885 ; \mathrm{p}<0.05)$. The greater the total number of blocks, the greater was also the number of blocks won $(r=0.600 ; p<0.05)$. Similarly, the greater total number of blocks was also accompanied by the greater number of block errors $(r=0.826 ; p<0.05)$.

Statistically significant correlation was found between the greater number of blocks won by a player and his higher efficiency of attack $(\mathrm{r}=0.550 ; \mathrm{p}<0.05)$.

\section{DISCUSSION}

Studies on men's volleyball have shown that there is a growing tendency to use tall players [7]. The current study also showed that taller players were used. While in Reilly's study the mean height in 1987 was $195 \mathrm{~cm}$ (SD 6.2), in the current study the mean height was $200 \mathrm{~cm}$ (SD 6.8). This comparison shows that players at the professional level have become $5 \mathrm{~cm}$ taller. The taller the player, the more probable it is that he is able to block the opponents' attack successfully or to direct the ball to the opponents' side of the court.

The results of our study also showed that taller players were more efficient than shorter ones at attack. In our study, the height of all the setters was below the average of the sample, but one of the setters was able to attack with the efficiency of $60 \%$. In our study, the setters performed fewer spikes than the average. The proficiency of setters can be deceptive, as for them, a few successful attacks can be sufficient to achieve high efficiency (the number of attacks is small).

Palao et al. [5] say in their article that, as setters have a significant role in building up the attack, older and more experienced players are used in that role. Our study, however, did not confirm that. Our study showed that setters' 


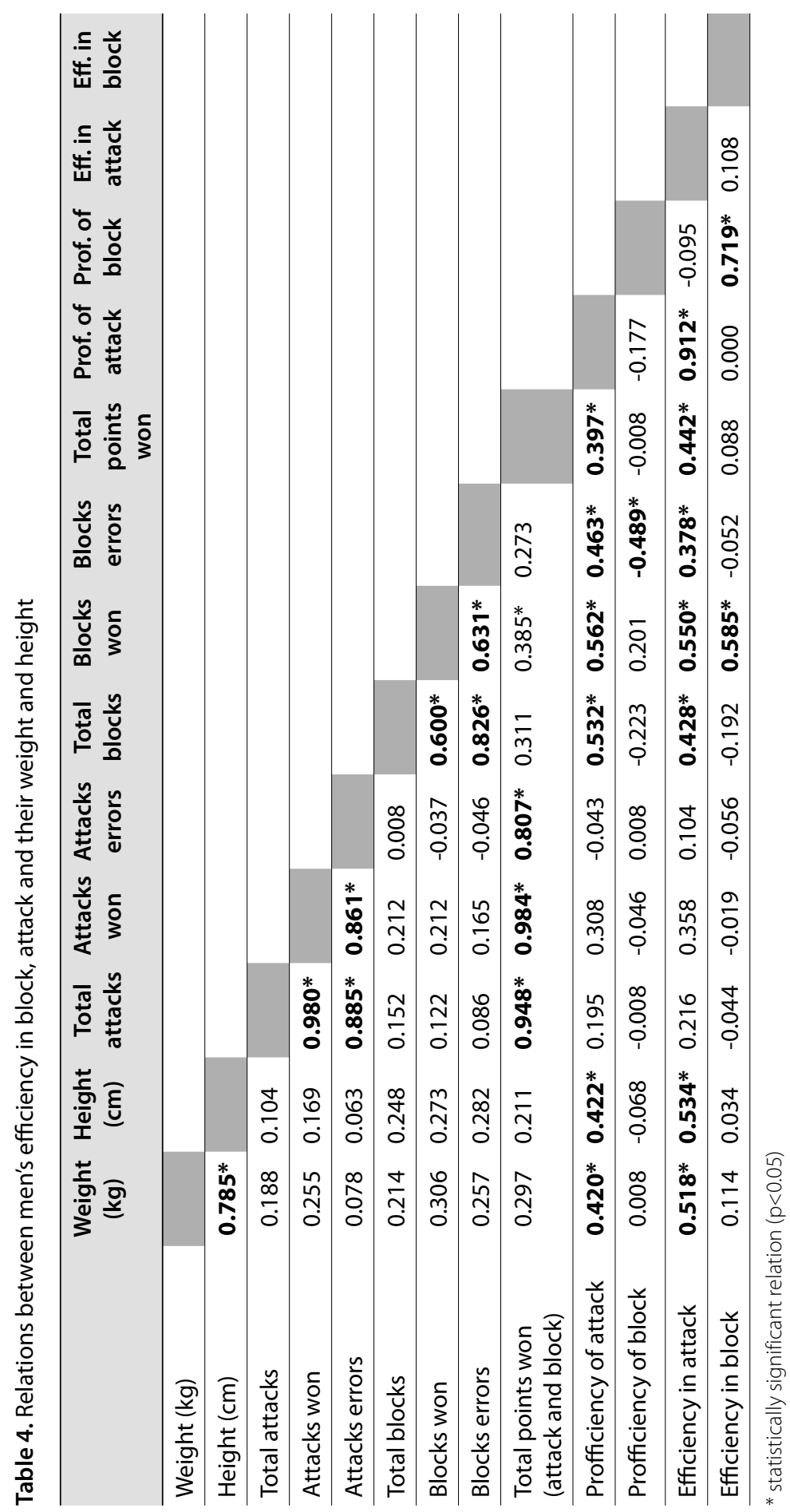


age was not significant at their selection. The youngest setter in the study was 19 years old, which means that he was the youngest player in the pool. The two oldest setters were both 36 years old, which made them the oldest players of the pool. The remaining two setters were of the mean age of the sample. It can be supposed that at the selection of setters, like of players in all the other positions, the player with the best technique for this position is used.

The block load in the current study coincided with Jeremy M. Sheppard's results of 2008 where it was found that the greatest load of block fell on middle blockers [8]. Our study also showed that most of the players who performed a greater number of blocks were middle blockers. Among them, the player who achieved the highest result performed 37 blocks; the two following players were also middle blockers - both of them performed 31 blocks. All the middle blockers in the current study were taller than the average of the sample, which supports the conclusion that taller players are used as middle blockers. Although the current study did not show any correlation between the performance of the block and the players' height, one can say that using taller players as middle blockers shows that useful blocking (the ball remains in possession of the blocking team) is as important as efficient block in present-day volleyball at the international level. Useful blocking gives the defending team the opportunity for setting up an attack again.

\section{CONCLUSION}

In the matches of Pool B of the European Championship 2015, the greatest load at attack was carried by outside attackers, while opposite attackers and middle blockers had the greatest load at block. Setters performed the smallest number of spikes.

At this tournament we found that the players' height correlated with the efficiency of attack $(r=0.534)$, and weight was also in correlation with the efficiency of attack $(r=0.518 ; \mathrm{p}<0.05)$. No statistically significant correlation was found between the efficiency of block and the players' weight and height. We can think that there can be more important influences for blocking efficiency than players' height and weight. These factors can be reaction speed, moving speed, timing and anticipation time, but we did not measure them in the current study. 


\section{REFERENCES}

1. Gabbett T., Georgieff B., Domrow N. (2007). The use of physiological, anthropometric, and skill data to predict selection in a talent-identified junior volleyball squad. Journal of Sports Sciences, 25(12), 1337-1344.

2. Gaurav V., Singh M., Singh S. (2010). Anthropometric characteristics, somatotyping and body composition of volleyball and basketball players. Journal of Physical Education and Sports Management, 1(3), 28-32.

3. Fattahi A., Ameli M., Sadeghi H., Mahmoodi B. (2012). Relationship between anthropometric parameters with vertical jump in male elite volleyball players due to game's position. Journal of Human Sport and Exercise, 7(3), 714-726.

4. Malousaris G.G., Bergeles N.K., Barzouka K.G., Bayios I.A., Nassis G.P., Koskolou M.D. (2008). Somatotype, size and body composition of competitive female volleyball players. Journal of Science and Medicine in Sport, 11(3), 337-344.

5. Palao J.M., Manzanares P., Valadés D. (2014). Anthropometric, Physical, and Age Differences by the Player Position and the Performance Level in Volleyball. Journal of Human Kinetics, 44, 223-236.

6. Prridal V., Hančák J. (2012). Effects of the quality of selected kinds of game skills of an individual on the set outcome in men's top-level volleyball. Acta Facultatis Educationis Physicae Universitatis Comenianae, 52(1), 49-60.

7. Reilly T., Secher N., Snell P., Williams C. (1990). Physiology of Sports. London: Spon Press.

8. Sheppard J.M., Cronin J.B., Gabbett T.J., McGuigan M.R., Etxebarria N., Newton R.U. (2008). Relative importance of strength, power and anthropometric measures to jump performance of elite volleyball players. Journal of Strength and Conditioning Research, 22(3), 758-765.

9. Silva M., Lacerda D., João P.V. (2013). Match analysis of discrimination skills according to the setter attack zone position in high level volleyball. Journal of Performance Analysis in Sport, 13(2), 452-460.

\section{Address for correspondence:}

Raini Stamm

Tallinn University

School of Natural Sciences and Health

Narva street 29, 10120 Tallinn, Estonia

E-mail: raini.stamm@tlu.ee 